\title{
American Black-White Differences in Primary Tooth Crown Shape: The Crown Index
}

\author{
Edward F. Harris* and Betsy D. Barcroft \\ Department of Pediatric Dentistry, University of Tennessee, Memphis.
}

ABSTRACT: The purpose of this tooth-size study was to compare the crown index - the ratio of buccolingal to mesiodistal crown size-in the primary teeth of contemporary American blacks and whites. Maximum $\mathrm{MD}$ and BL drown dimensions were obtained with sliding calipers from dental casts of children attending the graduate pedodontic and orthodontic clinics at the University of Tennessee, Memphis $(\mathrm{n}=226)$. The crown index (BL/MD times 100) was calculated for all 10 tooth types (left and right sides were averaged prior to calculation). Only the maxillary first molar exhibited a significant sex difference (girls have a higher crown index). In contrast, 9 of the 10 tooth types have signficantly higher

It is commonly appreciated that teeth differ among human groups both as regards shape as well as size. Part of this is due to differences in the prevalence and degree of crown traits, such as incisor shoveling (Hrdlička, 1920) and molar cusp number (Harris and Bailit, 1980), but other differences involve the proportionality of crown components such as relative cusp sizes (Turner et al., 1991; Townsend et al., 2003; Harris and Dinh, 2006)

Two of the prominent races in the United States are blacks and whites. The 2000 Census of the U.S. lists selfassessed proportions of blacks and whites at about $13 \%$ and $65 \%$, respectively. The dental anthropology of American blacks is not known as well as for the majority whites, partly because blacks are unevenly distributed geographically, being concentrated in the Southeast. Anthropological dental studies are primarily limited to tooth eruption and crown sizes. Studies document the early development of teeth in American blacks vis-à-vis American whites. We are aware of two studies of the primary dentition (both dealing with tooth emergence); both show a precedence of American blacks compared to American whites (Ferguson et al., 1957; Infante, 1974). The serial study of children from Tuskeegee, Alabama (Steggerda and Hill, 1942) and national U.S. epidemiological studies have collected data on the ages of emergence of the permanent teeth (Garn et al., 1972, 1973), but fewer data are available on crown sizes. The study by Richardson and Malhotra $(1975,1976)$ based on the Meharry growth study (Nashville, Tennessee) probably is the best known and most commonly cited study for the permanent teeth of American blacks $(\mathrm{n} \approx$ 160). Ferguson et al. (1978; Macko et al., 1979) reported crown indices in blacks than whites. Analysis of the MD and BL crown diameters reveals that the race differencs are due exclusively to differences in mesiodistal crown lengths; the buccolingual crown breadths do not differ between these two races. Consequently, the crown indices are higher in blacks because of their larger MD dimensions. Differences in the indices conform to prior findings that American blacks have larger tooth crowns than whites in both the primary and permanent dentitions, and this study shows that the differences are due to the MD not the BL crown axis. Study of the crown components will shed light on how the crown shapes differ between these two races. Dental Anthropology 2010;23(3):83-88.

on a sample of blacks $(\mathrm{n} \approx 113)$ from the University of Connecticut. Keene (1979) described mesiodistal crown lengths in black male U.S. Navy recruits (also Keene, 1967).

As for the primary dentition, Moss and colleagues (1966a,b) published data on Liberian (west-central Africa) primary tooth sizes, but sample sizes were small (8 to 19 extracted teeth per type, sexes combined). Hanihara (1976) studied a sample of blacks $(n \approx 65)$ at the University of Chicago. Vaughan and Harris (1992) described a sample of 100 blacks collected at the University of Tennessee. Anderson $(2005,2006,2007)$ described tooth crown sizes of a large sample $(n \approx 1,124)$ of American blacks from Howard University (Washington, D.C.)

To our knowledge, prior studies have been limited to the mesiodistal (MD) and buccolingual (BL) dimensions themselves, though Hanihara did employ multivariate statistics. The purpose of the present study is to compare tooth crown shapes - ratios of BL width to MD depth-in the primary teeth from samples of American blacks and whites from the U.S. Mid-South. This report was stimulated by exploratory findings that suggested that blacks have significantly different crown indices than whites, and the present study explores that finding in more detail.

${ }^{*}$ Correspondence to: Edward F. Harris, College of Dentistry, University of Tennessee, Memphis, Tennessee 38167.

E-mail: eharris@uthsc.edu 


\section{MATERIALS AND METHODS}

Full-mouth hydrocolloid casts were taken on children in the primary or early mixed dentitions. These were poured immediately in dental stone. Children were routine, phenotypically normal children attending the graduate pediatric or orthodontic dental clinic at the University of Tennessee, Memphis. Race (either black or white) was based on the parent's self-assessment (Edgar and Hunley 2009).

Total sample size was 226 with proportionate samples by race and sex. Maximum mesiodistal and buccolingual crown dimensions were measured as described by Seipel (1946) using sliding calipers with an electronic-readout precision of $0.005 \mathrm{~mm}$. Data were collated in an Excel ${ }^{\circledR}$ spreadsheet (Microsoft Corporation, Redmond, WA), and then uploaded to JMP ${ }^{\circledR}$ version 9 (SAS Institute Inc., Cary, NC) for statistical analysis.

All measurements were obtained twice. When the repeated measures differed by more than $0.2 \mathrm{~mm}$, which was rare, a third measurement was taken with the two closest values being averaged. Teeth were measured on both the left and right sides, and analysis is based on the left-right averages.

The random component of the intra-observer repeatability was calculated using the standard Dahlberg statistic:

$$
M E=\sqrt{\frac{\sum_{i=1}^{n}\left(x_{1 i}-X_{2 i}\right)^{2}}{2 n}}
$$

where $X_{1 \mathrm{i}}$ and $X_{2 \mathrm{i}}$ are the repeated measurements for case " $\mathrm{i}$ " and $\mathrm{n}$ is the number of cases (Dahlberg, 1940) and "ME" stands for method error. The Dahlberg statistic is 0.012 $\mathrm{mm}$. In other words, the standard error of the technical error of measurement (i.e., the error due to variability in measuring the teeth) is about one-hundredth of a millimeter. This is very small, and it does not account for any of the differences claimed to be significant statistically.

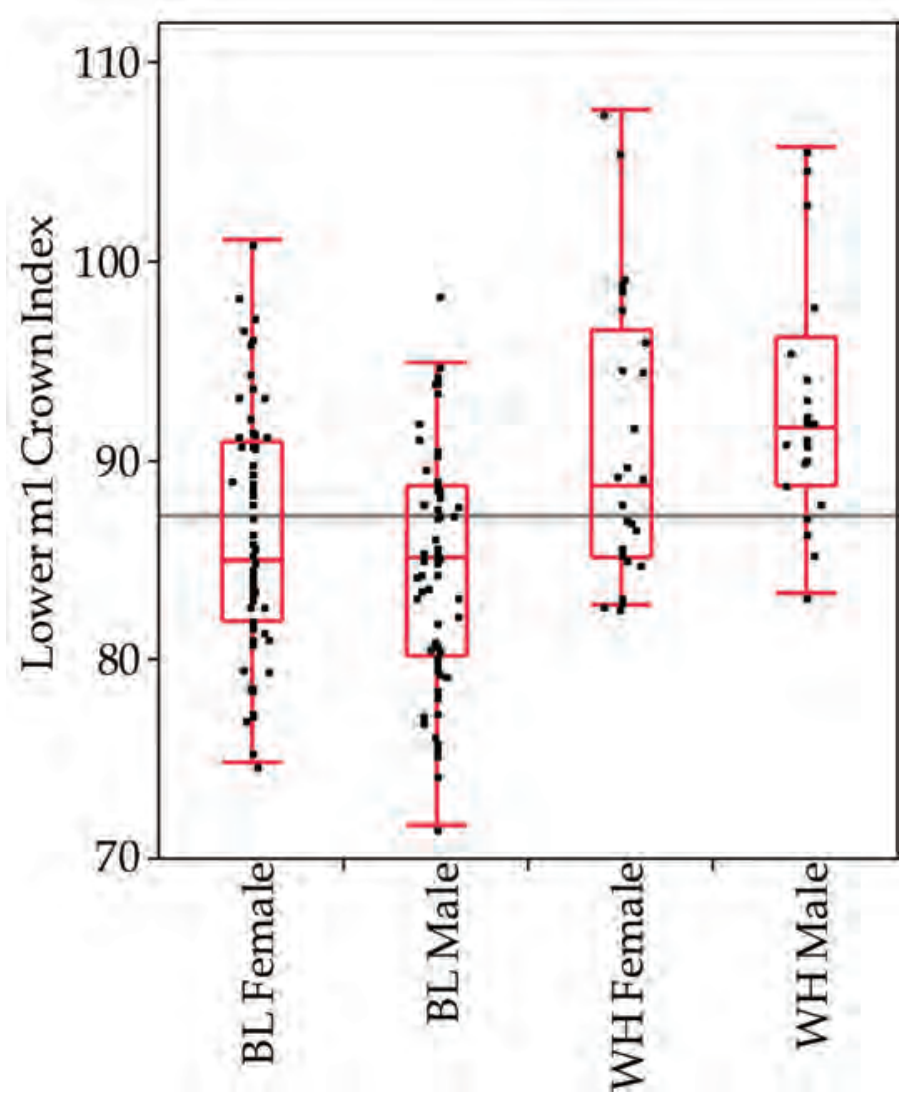

Fig 2. Boxplots for the crown index of the lower first molar. This tooth type has the largest F-ratio, and "race" accounts for $17 \%$ of the total variance. The raceby-sex interaction for this variable (Table 2) is due to the higher crown index in white girls compared to white boys, whereas there is no sex difference in the samples of blacks. The smaller index in blacks than whites is due to their greater MD crown length rather than any difference in BL breadth.

TABLE 1. Results of two-way analysis of variance for each of the 10 tooth types testing for a race and/or sex difference in the crown index

\begin{tabular}{|c|c|c|c|c|c|c|c|c|c|}
\hline \multirow{2}{*}{$\begin{array}{c}\text { Tooth } \\
\text { type }\end{array}$} & \multicolumn{3}{|c|}{ Race } & \multicolumn{3}{|c|}{ Sex } & \multicolumn{3}{|c|}{ Interaction } \\
\hline & $\overline{\mathrm{df}}$ & $F$ & $\overline{P \text { value }}$ & $\overline{\mathrm{df}}$ & $\mathrm{F}$ & P value & $\overline{\mathrm{df}}$ & $\mathrm{F}$ & P value \\
\hline \multicolumn{10}{|l|}{ Maxilla } \\
\hline i1 & 1 & 4.22 & 0.0421 & 1 & 0.01 & 0.9249 & 1 & 0.32 & 0.5742 \\
\hline i2 & 1 & 11.86 & 0.0008 & 1 & 1.89 & 0.1714 & 1 & 0.62 & 0.4332 \\
\hline c & 1 & 0.03 & 0.8658 & 1 & 1.02 & 0.3139 & 1 & 0.29 & 0.5902 \\
\hline $\mathrm{m} 1$ & 1 & 7.97 & 0.0053 & 1 & 11.99 & 0.0007 & 1 & 3.26 & 0.0728 \\
\hline $\mathrm{m} 2$ & 1 & 18.04 & $<0.0001$ & 1 & 2.27 & 0.1336 & 1 & 0.00 & 0.9470 \\
\hline \multicolumn{10}{|c|}{ Mandible } \\
\hline i1 & 1 & 10.95 & 0.0013 & 1 & 0.27 & 0.6031 & 1 & 1.84 & 0.1781 \\
\hline i2 & 1 & 4.66 & 0.0326 & 1 & 0.03 & 0.8588 & 1 & 0.65 & 0.4220 \\
\hline c & 1 & 10.50 & 0.0014 & 1 & 0.49 & 0.4859 & 1 & 0.02 & 0.8890 \\
\hline $\mathrm{m} 1$ & 1 & 40.20 & $<0.0001$ & 1 & 0.40 & 0.5302 & 1 & 5.36 & 0.0217 \\
\hline $\mathrm{m} 2$ & 1 & 16.18 & $<0.0001$ & 1 & 1.83 & 0.1773 & 1 & 0.47 & 0.4950 \\
\hline
\end{tabular}




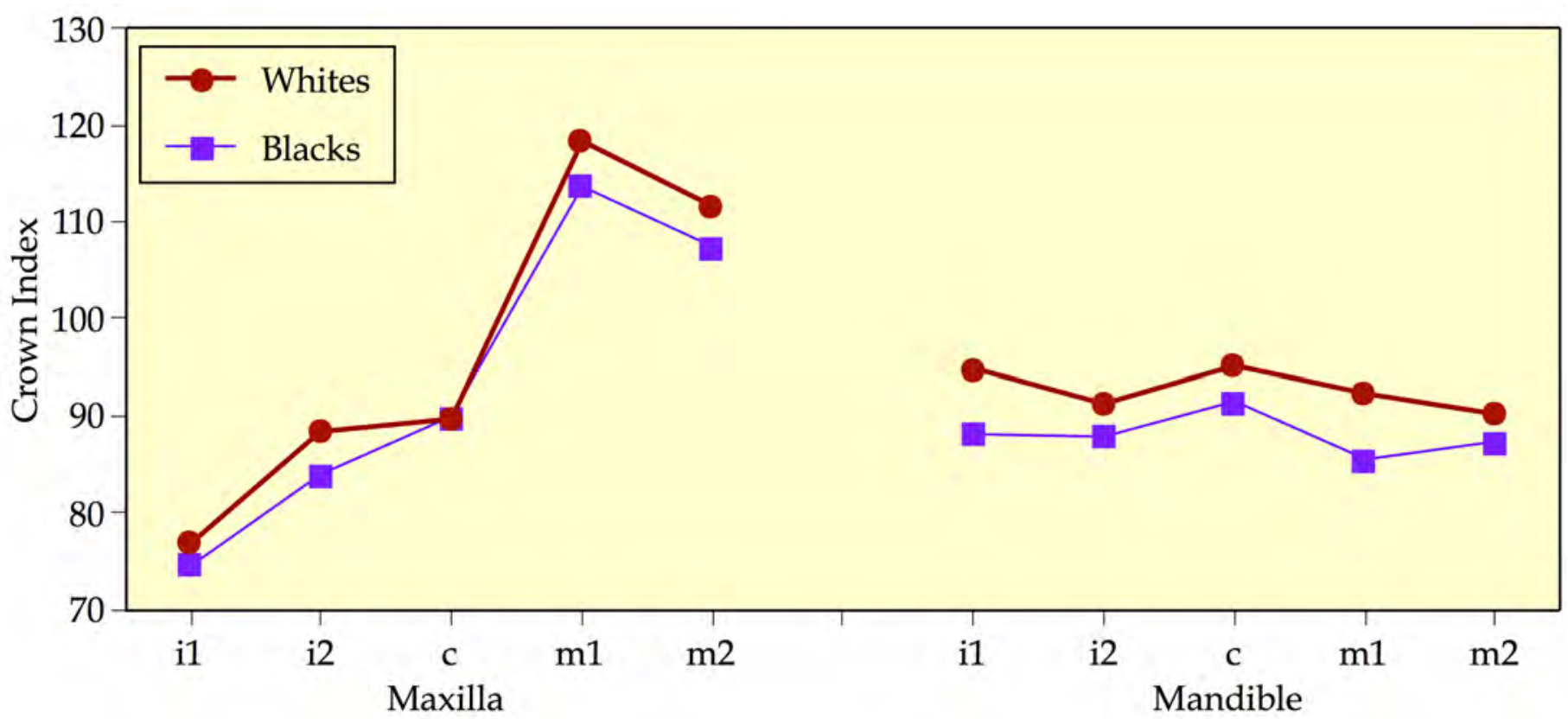

Fig. 1. Plot of the crown index, by race and tooth type (sexes pooled). The index is significantly lower in blacks for all tooth types excepting the maxillary canine. Only the maxillary molars exhibit indices greater than one (where BL breadth is larger than MD length).

In a complementary fashion, the percentage of measurement size due to technical error of measurement (Sokal and Rohlf, 1991) also was computed. The formula is:

$$
\frac{\left|X_{1}-X_{2}\right|}{\left(\frac{X_{1}+X_{2}}{2}\right)} \times 100
$$

The average difference is $0.18 \%$, meaning that the average percent of tooth size attributable to TEM is much less than $1 \%$ of the tooth's diameter.

The crown index (e.g., Hrdlička, 1923; Thomsen, 1955; Hillson, 1996) is a measure of crown shape based on the

TABLE 2. Results of one-way ANOVA testing for black-white differences in the crown index (sexes pooled)

\begin{tabular}{rrrrr}
\hline Tooth & $\mathrm{r}^{2}(\%)$ & $\mathrm{n}$ & F ratio & P value \\
\hline \multicolumn{5}{c}{ Maxilla } \\
$\mathrm{i} 1$ & 3.25 & 125 & 4.13 & 0.0442 \\
$\mathrm{i} 2$ & 7.01 & 148 & 11.01 & 0.0011 \\
$\mathrm{c}$ & 0.01 & 182 & 0.02 & 0.8816 \\
$\mathrm{~m} 1$ & 4.91 & 183 & 9.35 & 0.0026 \\
$\mathrm{~m} 2$ & 9.49 & 179 & 18.57 & $<0.0001$ \\
& \multicolumn{5}{c}{ Mandible } \\
$\mathrm{i} 1$ & 10.18 & 108 & 12.02 & 0.0008 \\
$\mathrm{i} 2$ & 3.54 & 137 & 4.96 & 0.0276 \\
$\mathrm{c}$ & 5.55 & 188 & 10.93 & 0.0011 \\
$\mathrm{~m} 1$ & 17.57 & 181 & 38.16 & $<0.0001$ \\
$\mathrm{~m} 2$ & 7.86 & 184 & 15.53 & 0.0001 \\
\hline
\end{tabular}

two commonly-measured crown dimensions, namely maximum mesiodistal and buccolingual diameters. This index is buccolingual crown size expressed as a percentage of mesiodistal crown size,

$$
\left(\frac{\mathrm{BL}}{\mathrm{MD}}\right) \times 100
$$

A tooth with a large crown index has a buccolingually broad crown relative to its mesiodistal length; conversely, a small crown index means the tooth is narrow in relation to it length.

Analysis relied on analysis of variance (Winer et al., 1991; Sokal and Rohlf, 1995). Initial tests used two-way ANOVA to evaluate race and sex differences, but sex differences are uncommon, so a one-way model was used to simplify presentation and recover the degrees of freedom. Statistical significance was set at the conventional level of alpha $=0.05$, and no correction was made for multiple comparisons.

\section{RESULTS}

Applying two-way ANOVA to the 10 tooth types (Table 1) disclosed that sex differences are uncommon (only the lower first molar), but that black-white race differences are prevalent. Indeed, of the 10 tooth types, only the maxillary canine fails to exhibit a significant black-white difference in the crown index. Consequently, "sex" was dropped from the model, and the one-way ANOVA results (Table 2) produce the same interpretation, namely that the crown index is consistently lower in blacks than whitesthat the crowns are mesiodistally longer in blacks than 
whites relative to their buccolingual crown widths. In terms of explained variance $\left(\mathrm{r}^{2}\right)$, the largest F-ratio is for the mandibular first molar (Fig. 1), where "race" accounts for $17 \%$ of the total variance. This percentage is less than $10 \%$ for the other tooth types.

The patterns of crown indices among tooth types are illustrated in Figure 2. The patterns differ between arches, notably because of the high values for the two maxillary molars, which are the only teeth with indices above 100\% (BL breadths $>$ MD lengths). Based on paired t-tests, the index is significantly higher for the upper lateral incisor than the adjacent central incisor both in blacks and whites $(\mathrm{P}<0.0001)$. Comparably, the index is significantly lower for the upper second molar than the first $(\mathrm{P}<0.0001)$

The pattern is less consistent in the mandible. Evaluated with paired t-tests, the crown index for i1 and i2 is virtually identical in blacks $(P=0.996)$, but there is a significant i1-to-i2 drop in the white sample $(\mathrm{P}=0.03)$. Between the lower molars, blacks exhibit a significant $\mathrm{m} 1$-to-m2 increase in the index $(\mathrm{P}=0.0003)$ whereas this gradient drops significantly in whites $(\mathrm{P}=0.04)$.

As with any ratio, there are at least three possibilities for the race differences in crown indices: The numerators may differ between groups, the denominators may differ, or both. All 20 of the tooth dimensions were surveyed (Table 3), and none of the 10 buccolingual dimensions was significantly different between blacks and whites. In contrast, 7 of the 10 mesiodistal dimensions were significantly different between these two groups. The interpretation of differences in the crown index between blacks and whites is, thus, greatly simplified; the differences in the crown indices are due to blacks possessing teeth that are disproportionately long in relation to their buccolingual breadths.

\section{DISCUSSION}

The crown index has historically been used to characterize the width-length relationship of the molars, but there is no conceptual reason for this. The index is equally informative across all tooth types (e.g., GarciaGodoy and Townsend, 1984; Foster and Harris, 2009).

It was unanticipated that the crown indices would be statistically identical between boys and girls (Table 1) because this suggests that sexual dimorphism does not measurably influence tooth shape. The level of dimorphism is less in the primary than the permanent dentition (Harris and Lease, 2005), but it certainly exists, and some authors (DeVito and Saunders, 1990; Zadzińska et al., 2008; Adler

TABLE 3. Results of two-way ANOVAs testing for race and sex differences in crown size

\begin{tabular}{crrrrrr}
\hline Tooth & Race & P & F Sex & Interaction & Adjusted \\
Percent $\mathrm{r}^{2}$
\end{tabular}


and Donlon, 2010) have explored its use in estimating the sex of human remains in forensic settings. The present results suggest that, at least by this metric, the larger teeth of boys are isometrically enlarged versions of the crown shapes in girls.

These results raise the issue of population differences: This study found essentially no evidence of sexual dimorphism in either the black or white sample. In contrast, Margetts and Brown (1978) study of Yuendumu Australians found that the indices of primary teeth tend to be higher in boys. Garcia-Godoy and Townsend (1984), in contrast, found higher indices in girls in their sample of Dominican mulatto (black-white) children. These population differences discount stereotypes that humans are monomorphic. Early extrapolations to all groups (e.g., Garn et al., 1967a,b) actually stemmed from the paucity of information on racial differences.

Nine of the 10 black-white comparisons by tooth type (Table 2) are highly significant statistically. Only the maxillary canine has the same shape relationship in the two groups. For all of the other tooth types, blacks have a significantly lower crown index. It is well appreciated that American blacks have larger crown dimensions than whites absolutely-both as regards the primary (e.g., Vaughan and Harris, 1992; Anderson, 2005) and permanent (Richardson and Malhotra, 1975) dentitions-and the results here indicate that the groups also differ in their width-to-length relationships. Interestingly, interpretation is greatly simplified when (Table 3) it is noted that none of the buccolingual crown dimensions differs significantly. This shows that the lower crown indices seen in blacks are due to the mesiodistal dimension. The primary teeth in American blacks have smaller crown indices than whites because their tooth crowns are larger mesiodistally.

All of the primary teeth are established and begin crown mineralization during the second trimester in utero (Lunt and Law, 1974), so whatever the causes of mesiodistally larger teeth in American blacks - such as up-regulation of mitotic rates - are initiated early in development. Nothing is known about the primary teeth, but the permanent teeth form and emerge faster in blacks than whites (Steggerda and Hill, 1942; Harris and McKee, 1990), even though the teeth are larger. Making larger teeth in a shorter time suggests that the mitotic rates are faster; there seem to be no data suggesting that the quality of enamel or dentin differ between blacks and whites. Hall et al. (2007) found that enamel was thicker in blacks than whites - which again suggests a difference in growth tempos - though the differences in enamel do not account for the larger overall crown differences.

One might suppose that mesiodistally larger teeth would translate into a greater risk of crowding-where arch size (determined by the supporting basal bones) is inadequate for proper alignment of the larger teeth. In fact, dental crowding (inadequate arch size) is not more common in American blacks than whites (Kelly and Harvey, 1977; Brunelle et al., 1996). On the contrary, the prevalence of interdental spacing is appreciably higher in blacks than whites. The lack of an increased risk of crowding is due to the disproportionately large arches in blacks (Burris and Harris, 1998). As Ross-Powell and Harris (2001) show, this race difference is ostensible from early in the primary dentition.

Prior work in our lab (Harris et al., 2001) suggest that differences in the crown sizes of American blacks and whites are primarily due to differences in size of the dental pulps. Developmentally, size of the pulp is defined by the growth of the enamel epithelium - which, in the mature tooth, is the interface between the enamel and dentineprior to mineralization. The present results suggest that growth of the premineralized tooth bud is different in blacks and whites - that growth favors the mesiodistal axis in blacks, creating a different crown shape.

\section{REFERENCES CITED}

Adler CJ, Donlon D. 2010. Sexual dimorphism in deciduous crown traits of a European derived Australian sample. Forensic Sci Int 199:29-37.

Anderson AA. 2005. Dentition and occlusion development in African American children: mesiodistal crown diameters and tooth-size ratios of primary teeth. Pediatr Dent 27:121-128.

Anderson AA. 2006. Occlusal development in children of African American descent. Types of terminal plane relationships in the primary dentition. Angle Orthod 76:817-823.

Anderson AA. 2007. The dentition and occlusal development in children of African American descent. Angle Orthod 77:421-429.

Brunelle JA, Bhat M, Lipton JA. 1996. Prevalence and distribution of selected occlusal characteristics in the US population, 1988-1991. J Dent Res 75:706-13.

Burris BG, Harris EF. 1998. Identification of race and sex from palate dimensions. Journal of Forensic Sciences 43:959-963.

Dahlberg G. 1940. Statistical methods for medical and biological students. London: George Allen and Unwin.

DeVito C, Saunders SR. 1990. A discriminant function analysis of deciduous teeth to determine sex. J Forensic Sci 35:845-858.

Edgar HJ, Hunley KL. 2009. Race reconciled?: How biological anthropologists view human variation. Am J Phys Anthropol 139:1-4.

Ferguson FS, Macko DJ, Sonnenberg EM, Shakun ML. 1978. The use of regression constants in estimating tooth size in a Negro population. Am J Orthod 73:68-72.

Foster CL, Harris EF. 2009. Discriminatory effectiveness of crown indexes - tests between American blacks and whites. Dental Anthropology 22:85-92.

Garcia-Godoy F, Townsend GC. 1984. Crown indices of the deciduous teeth in Dominican mulatto children. Acta Odondol Pediatr 5:25-27. 
Garn SM, Lewis AB, Kerewsky RS. 1967b. Sex difference in tooth shape. J Dent Res 46:1470.

Garn SM, Lewis AB, and Kerewsky RS. 1967b. Shape similarities throughout the dentition. J Dent Res 1967;46:1481.

Garn SM, Sandusky ST, Nagy JM, Trowbridge FL. 1973. Negro-Caucasoid differences in permanent tooth emergence at a constant income level. Arch Oral Biol 18:609-615.

Garn SM, Wertheimer F, Sandusky ST, McCann MB. 1972. Advanced tooth emergence in Negro individuals. J Dent Res 51:1506.

Hall NE, Lindauer SJ, Tüfekçi E, Shroff B. 2007. Predictors of variation in mandibular incisor enamel thickness. J Am Dent Assoc 138:809-815.

Hanihara K. 1976. Statistical and comparative studies of the Australian Aboriginal Dentition. University Museum, University of Tokyo, Bulletin No. 11.

Harris EF, Bailit HL. 1980. The metaconule: a morphologic and familial analysis of a molar cusp in humans. Am J Phys Anthropol 53:349-358.

Harris EF, Dinh DP. 2006. Intercusp relationships of the permanent maxillary first and second molars in American whites. Am J Phys Anthropol 130:514-528.

Harris EF, Hicks JD, Barcroft BD. 2001. Tissue contributions to sex and race differences in tooth crown size of deciduous molars. Am J Phys Anthropol 115:223-237.

Harris EF, Lease L. 2005. Mesiodistal tooth crown dimensions of the primary dentition: a worldwide survey. Am J Phys Anthropol 128:593-607.

Harris EF, McKee JH. 1990. Tooth mineralization standards for blacks and whites from the middle southern United States. J Forensic Sci 35;859-872.

Hillson S. 1996. Dental anthropology. Cambridge: Cambridge University Press.

Hrdlička A. 1920. Shovel-shaped teeth. Am J Phys Anthropol 3:429-465.

Hrdlička A. 1923. Variations in the dimensions of lower molars in man and anthropoid apes. Am J Phys Anthropol 6:423-438.

Infante PF. 1974. Sex differences in the chronology of deciduous tooth emergence in white and black children. J Dent Res 53:418-421.

Keene HJ. 1967. Australopithecine dental dimensions in a contemporary population. Am J Phys Anthropol 27:379-383.

Keene HJ. 1979. Mesiodistal crown diameters of permanent teeth in male American Negroes. Am J Orthod 76:95-99.

Kelly JE, Harvey CR. 1977. An assessment of the occlusion of youths 12-17 years. United States Public Health Service, Vital and Health Statistics, series 11, no. 162.

Lunt RC, Law DB. 1974. A review of the chronology of calcification of deciduous teeth. J Am Dent Assoc 89:599-606.

Macko DJ, Ferguson FS, Sonnenberg EM. 1979. Mesiodistal crown dimensions of permanent teeth of black Americans. ASDC J Dent Child 46:314-318.
Margetts B, Brown T. 1978. Crown diameters of the deciduous teeth in Australian aboriginals. Am J Phys Anthropol 48:493-502.

Moss ML, Chase PS. 1966a. Morphology of Liberian Negro deciduous teeth. I. Odontometry. Am J Phys Anthropol 24:215-229.

Moss ML, Chase PS. 1966b. Morphology of Liberian Negro deciduous teeth. II. Arch dimensions and occlusion. Am J Phys Anthropol 25:261-275.

Richardson ER, Malhotra SK. 1975. Mesiodistal crown dimension of the permanent dentition of American Negroes. Am J Orthod 68:157-164.

Richardson ER, Malhotra SK. 1976. Recent findings on the mesiodistal diameter of the crowns of the permanent dentition of American blacks. Q Natl Dent Assoc 34:4451.

Ross-Powell RE, Harris EF. 2001. Growth of the anterior dental arch in African-American children: a longitudinal study from 3-18 years of age. Am J Orthod Dentofacial Orthop 118:649-657.

Seipel C. 1946. Variation in tooth position: a metric study of variation and adaptation in the deciduous and permanent dentitions. Swed Dent J 39:1-176.

Sokal RR, Rohlf FJ. 1995. Biometry: the principles and practice of statistics in biological research, 3rd ed. San Francisco: W.H. Freeman and Company.

Steggerda M, Hill TJ. 1942. Eruption time among Whites, Negroes and Indians. Am J Orthod Oral Surg 28:361370.

Thomsen S. 1955. Dental morphology and occlusion in the people of Tristan da Cunha. Results of the Norwegian Scientific Expedition to Tristan da Cunha, 1937-1938, No. 25. Oslo: Det Norske Videnskaps-Akademi.

Townsend G, Richards L, Hughes T. 2003. Molar intercuspal dimensions: genetic input to phenotypic variation. J Dent Res 82:350-355.

Turner CG II, Nichol CR, Scott GR. 1991. Scoring procedures for key morphological traits of the permanent dentition: the Arizona State University dental anthropology system. In: Kelley MA, Larsen CS, editors. Advances in dental anthropology. New York: Wiley-Liss, p 13-31. Vaughan ME, Harris EF. 1992. Deciduous tooth size standards for American Blacks. J Tenn Dent Assoc 72:30-33.

Winer BJ, Brown DR, Michels KM. 1991. Statistical principles in experimental design. 3rd ed. New York: McGraw-Hill Book Company.

Zadzińska E, Karasińska M, Jedrychowska-Dańska K, Watala C, Witas HW. 2008. Sex diagnosis of subadult specimens from Medieval Polish archaeological sites: metric analysis of deciduous dentition. Homo 59:175187. 